sciendo

\title{
A Refutação da Teoria Empirista da Consciência
}

M. S. Lourenço

LanCog, Universidade de Lisboa

Disputatio Vol. 3, No. 27

November 2009

DOI: $10.2478 /$ disp-2009-0013

ISSN: 0873-626X 


\title{
A refutação da teoria empirista da consciência*
}

\author{
M. S. Lourenço \\ Universidade de Lisboa
}

\section{A concepção empirista da res cogitans}

A finalidade deste capítulo é proporcionar uma descrição dos princípios mais gerais que são utilizados nas discussões de Wittgenstein acerca da natureza da experiência dita interior ${ }^{1}$. Dois géneros principais de argumentos devem ser em in limine separados:

i) Argumentos acerca da possibilidade de determinar se a natureza da experiência interior é privada, num sentido da palavra «privado» a ser definido oportunamente; $\mathrm{e}$

ii) Argumentos acerca da possibilidade de determinar a natureza do meu conhecimento da consciência de outrem; em particular, se o meu conhecimento da consciência de outrem é para ser considerado como sendo apenas indutivo ou analógico.

$\mathrm{Ambas}^{2}$ as questões caem dentro do âmbito da questão mais geral que consiste em determinar que género de relação existe dentre as experiências ditas interiores e a sua representação linguística ou, melhor ainda, que género de relação existe entre as expressões da linguagem 1987).

* Capítulo 2 de Espontaneidade da Razão, de M. S. Lourenço (Lisboa: INCM,

${ }^{1}$ Acerca do problema da caracterização geral da natureza em Philosophische Untersuchungen e Zettel ver Malcolm, Norman «Wittgenstein on the Nature of Mind» in Studies in the Theory of Knowledge (1970), pp. 9-29. O emprego do termo consciência no texto é para ser compreendido exactamente como o termo alemão Bewußtsein.

${ }^{2}$ Destes dois géneros de argumento de carácter geral seguem-se dois corolários principais, um acerca das relações entre as linguagens $L_{p}$ e $L$ e outro acerca da possibilidade de eliminar prefixos como «eu sei» em contextos como «eu sei que $X$ » quando $X$ é uma descrição de um estado de consciência.

Disputatio, Vol. III, No. 27, November 2009 
natural que se referem a experiências interiores e estas mesmas experiências. Exemplos conhecidos destas experiências são, do ponto de vista perceptivo, as sensações e as percepções, do ponto de vista afectivo as emoções, do ponto de vista volitivo as intenções, do ponto de vista cognitivo os conceitos e os juízos.

Como já foi observado no capítulo anterior, um aspecto crucial da nova orientação filosófica de Wittgenstein é a sua rejeição do que então chamámos essencialismo, uma concepção segundo a qual é possível determinar o sentido de uma expressão acerca de um objecto $S$ através da determinação da essência de $S$. Assim, à luz da rejeição do essencialismo já descrita, não nos esforçaremos por determinar o género de relação que existe entre as expressões da linguagem natural que se referem a experiências interiores e estas mesmas experiências através da determinação da sua essência. De acordo com os resultados introduzidos no capítulo anterior, não procuraremos adivinhar qual é o sentido de uma expressão acerca de uma sensação mas, antes, procuraremos seguir o modelo proposto por Wittgenstein, nomeadamente o de considerar uma sensação em particular, no seu exemplo a sensação de dor. Tentaremos assim, através de uma discussão do que é a determinação do sentido de expressões que se referem à experiência interior de dor, ganhar a possibilidade de compreender a relação que existe entre a experiência interior e a sua representação linguística. O nosso primeiro objectivo é agora o de delinear a concepção pressuposta nos argumentos de teor empirista acerca da natureza da existência interior e da sua relação com os meios linguísticos que a representam.

Segundo a concepção a delinear, a minha experiência interior - $\mathrm{e}$ portanto as minhas sensações, percepções, emoções e intenções — só a mim próprio diz respeito e é, neste sentido, uma experiência puramente privada. Não é de todo possível que uma outra pessoa tenha acesso à minha consciência, e aí procure ter as experiências que eu neste momento estou a ter. No caso do exemplo proposto por Wittgenstein, só me é possível determinar o que se pode entender por uma dor quando eu observo, à luz de minha própria experiência interior de dor, i.e., das minhas sensações de dor, o que é que constituí para mim a experiência de dor. Logo, o método que se utiliza para chegar à formulação do conceito geral de uma dor é o método indutivo que consiste em observar em cada caso o que é que constitui, para o caso sob consideração, a experiência de dor e daí inferir para o caso geral, sendo assim a experiência privada que constitui o fundamento 
do conceito geral. Ao tentar compreender o sentido da palavra «dor» não tenho mais a fazer do que me recordar do que é minha experiência de dor, e assim o sentido da palavra «dor» é a experiência interior de dor que se observa na anamnese. Quando a seguir me pergunto como me será possível obter uma compreensão do que é a experiência de dor de outrem, por exemplo a experiência de dor de Job, a resposta é que simplesmente se torna suficiente transferir para a experiência interior de Job aquilo que constitui a minha própria experiência interior e portanto, pela utilização desse método indirecto, chego a poder determinar em que é que consiste a experiência de dor de Job.

Esta transferência do meu caso privado e pessoal para o caso de Job pode ser entendida, por sua vez, sob duas formas. Na primeira destas formas trata-se do conhecimento da experiência de Job, como uma experiência de dor, só me ser acessível através do processo indirecto, nomeadamente o da inferência analógica já referida. $\mathrm{Na}$ segunda das formas de transferência trata-se de que a designação da experiência de Job como sendo uma experiência de dor é indirecta agora no sentido que, ao ser aplicada não ao meu próprio caso mas ao caso de Job, só o posso fazer através da observação dos sintomas periféricos uma vez que, ex hypothesi ${ }^{3}$, as experiências interiores de Job, as suas experiências de dor, não me podem ser imediatamente dadas na minha consciência. Finalmente resta observar que ainda que a transferência da minha compreensão do sentido da palavra «dor», através da consideração da minha experiência de dor, fosse suficiente para entender a compreensão da experiência de dor e, correspondentemente, do sentido que para Job tem a palavra «dor», a minha própria experiência difere ainda essencialmente da experiência de Job. Em primeiro lugar, como já foi observado no capítulo anterior, segundo a teoria que delineámos, a palavra «dor» só adquire o seu sentido através de sua conexão com as imagens mentais na minha própria consciência, das minhas experiências privadas de dor e, em segundo lugar, do ponto de vista epistemológico, a evidência da minha percepção de mim próprio leva-me a concluir que só acerca de mim próprio é que posso ter conhecimento acerca da possibilidade de ter ou não uma dor, enquanto acerca de Job só posso ter uma crença acerca da possibilidade de Job ter ou não uma dor que diz que tem,

\footnotetext{
${ }^{3}$ A hipótese que serve de postulado ao argumento empirista consiste na proposição de que só existe acesso ao que é imediatamente dado na consciência.
} 
uma vez que no seu caso não consigo ter acesso à sua dor mas apenas às suas expressões de dor, i.e., aos seus sentimentos periféricos, estando assim sujeito às diversas possibilidades de erro na interpretação dos seus sintomas.

Terminamos aqui a delineação das concepções normalmente aduzidas a favor da caracterização da natureza da experiência interior como sendo essencialmente privada de tal modo que o meu conhecimento da minha própria consciência é o único fundamento para a compreensão do que é a consciência de outrem. Da consciência de outrem não chego nunca pois a ter verdadeiramente conhecimento. A estrutura e subtileza dos argumentos de Wittgenstein contra a concepção delineada será posta em evidência através da sua disposição gradual. Essencialmente, trata-se, segundo Wittgenstein, nos argumentos aduzidos a favor da concepção exposta da consciência, de uma análise adequada do que é a natureza da linguagem e, em particular, do emprego de expressões cuja denotação são sensações.

\section{A demonstração da inexistência da linguagem $L_{p}$}

Começaremos agora a exposição da doutrina de Wittgenstein acerca da natureza da consciência pelo exame da hipótese, já delineada na secção anterior, segundo a qual a única fundamentação do conceito geral de dor reside na minha experiência privada de dor. Aproveitamos agora a ocasião para observar que esta hipótese, associada na secção anterior apenas com a filosofia idealista, tem sido de facto usada, explícita ou implicitamente, no período da Filosofia Moderna, por outros filósofos além dos proponentes da doutrina idealista. Obviamente a hipótese aparece em Descartes, uma vez que, na quinta das suas Meditações Metafísicas, Descartes defende a ideia de que o conhecimento certo só se encontra representado no conhecimento que eu tenho da minha própria consciência, em comparação com a qual o mundo dito exterior e portanto a consciência de outrem me aparece como sendo sujeita a dúvida. A hipótese da natureza essencialmente privada da consciência e, em particular, de uma correspondente linguagem privada, é dominante na filosofia de Locke. Com efeito, segundo Locke, no meu diálogo com o leitor desta página, cada palavra que eu escrevo, por exemplo a palavra «meditação», só é compreensível para o leitor através de uma associação, que o leitor realiza na sua consciência, cujo conteúdo é a imagem mental causada 
pela palavra escrita por mim. Esta, por sua vez, é apenas para ser considerada como um sinal da imagem mental que eu associo à palavra «meditação». Assim, a palavra «meditação» constitui uma imagem do que é a minha imagem mental não sendo por isso possível ao leitor desta página fazer a mesma associação que eu faço e chegar assim à mesma imagem mental. A concepção de Locke sobrevive no empirismo contemporâneo, em particular na sua formulação fenomenalista. Nesta formulação procura-se representar os objectos do mundo exterior apenas como construções efectuadas a partir dos dados dos sentidos do sujeito cognoscente. As asserções que se fazem acerca dos objectos do mundo exterior têm que ser reescritas, à luz da concepção fenomenalista, sob a forma de asserções acerca dos dados dos sentidos do sujeito cognoscente. Estes dados do sentido são de natureza puramente privada, no sentido em que nenhum outro sujeito cognoscente pode ter os dados dos sentidos que eu tenho em cada momento dado. De um modo geral, pois, aproveitamos a ocasião para generalizar a adopção da hipótese a todas as concepções que se referem ao problema do fundamento do nosso conhecimento acerca do mundo exterior, e das diversas análises propostas para legitimar epistemologicamente asserções acerca da existência do mundo exterior e da consciência de outrem ${ }^{4}$.

Como o que é peculiar e inovador na posição de Wittgenstein não é tanto o facto de se opor à orientação predominante da filosofia moderna mas antes a sua descoberta de que o que é essencial a esta orientação é a concepção da existência de uma linguagem essencialmente privada, esforçar-nos-emos agora por definir em que condições é que a linguagem pode ser considerada essencialmente privada ${ }^{5}$. Para alcançar esta definição convém começar por observar que o que temos em mente definir é uma linguagem que é privada mas não no sentido contingente de ser uma linguagem falada por um único indivíduo, em contraste com uma linguagem falada por uma comunidade de indivíduos, ou ainda de ser uma linguagem contingentemente

${ }^{4} \mathrm{Na}$ filosofia da matemática de inspiração idealista, está concepção é elegantemente defendida por Brouwer na sua comunicação «Consciousness, Philosophy and Mathematics» in International Congress on Philosophy X, Amesterdão, 1948.

${ }^{5}$ Para a definição da linguagem $L_{p}$ é útil ter em mente o ensaio de Castañeda, Hector-Neri, «The Private Language Problem» in The Encyclopedia of Philosophy, org. Paul Edwards, Nova Iorque, pp. 458-464. 
privada no sentido de ser a linguagem secreta de uma única pessoa que possui além desta, a sua linguagem pública ${ }^{6}$.

A minha linguagem é privada, para Wittgenstein, no sentido essencial em que não é possível a outra pessoa, além de mim próprio, compreender o sentido das expressões que eu emprego. A razão pela qual é impossível que outra pessoa compreenda a minha linguagem privada é porque as expressões de minha linguagem privada têm como denotação as minhas experiências interiores, às quais só eu posso ter acesso na minha consciência. Neste sentido essencial a minha linguagem privada implica de facto dois géneros de privacidade, nomeadamente a privacidade de posse, no sentido em que as experiências interiores denotadas na minha linguagem só podem ser minhas e ainda a privacidade epistemológica, no sentido em que só eu posso ter conhecimento do que são as experiências interiores a que a minha linguagem privada se refere.

Em particular, alcançamos uma ideia da estrutura presumível de uma tal linguagem considerando o que seria nesta linguagem uma proposição elementar. Para a construção destas proposições o que é essencial é dispor dos nomes de que as proposições elementares são compostas e estes, por sua vez, poderão ser formados através da concentração da atenção numa dada sensação $S$, à qual é a seguir atribuída um nome, digamos «S» e finalmente fixar na minha memória a conexão entre o nome ou a designação da sensação e a própria sensação. A partir destes nomes, assim definidos, chego à possibilidade de, através da iteração destas operações privadas de definição, construir a minha linguagem privada. Trata-se pois essencialmente de que me é possível estabelecer uma conexão entre uma palavra $P$ da minha linguagem privada $L_{p}$ e uma sensação $S$, uma conexão que fixo na minha memória. O corolário óbvio deste processo de construção da minha linguagem privada $L_{p}$ é que o nome «S» será ainda, no futuro, o nome da sensação $S$ sempre que esta sensação se oferece à minha atenção ${ }^{7}$. Finalmente, podemos concluir esta definição de "privado» com a aposição das duas observações que se seguem. Em primeiro

\footnotetext{
${ }^{6}$ Ver a análise desta pressuposição e seu uso em argumentos recentes contra a posição de Wittgenstein aqui descrita em Hacker, P. M. S., «Private Language and Public Speakers» in Insight and Illusion, Clarendon Press, Oxford, 1972, p. 215 e segs.

${ }^{7}$ Assim a linguagem privada $L_{p}$ consiste em definições $D_{1}, \ldots, D_{n}$ de nomes de sensações $D_{i}(S)$ tais que, a definição $D_{t}(S)$ num dado momento $t$ é condição necessária e suficiente da definição $D_{t \cup k}(S)$ num momento $t \cup k$, com $t<k$.
} 
lugar tem-se, como corolário da definição de «privado», que não se trata de determinar se seria possível a Robinson Crusoe desenvolver uma linguagem de que ele seria o único utente, uma vez que Robinson Crusoe, embora só na ilha, poderia desenvolver uma linguagem que fosse susceptível de ser compreendida por outrem, ao contrário da linguagem $L_{p}$. Em segundo lugar, o sentido de «possível» (ou impossível) usado nestas discussões é o sentido forte de possível, nomeadamente logicamente possivel (ou impossivel). Neste sentido o conceito da existência de uma linguagem privada é impossível por permitir a derivação de uma contradição. Exemplos do mesmo género de impossibilidade são os conceitos de, e.g., «objecto azul inextenso» ou «esferas de 5 faces».

Passamos agora à exposição dos argumentos de Wittgenstein contra a hipótese da existência de uma linguagem privada no sentido de «privado» que acabamos de precisar. Wittgenstein começa por observar que o meu último passo na construção de nomes de $L_{p}$, nomeadamente a sua fixação na minha memória, significa de facto que no futuro terei de que ter a recordação certa da conexão entre o nome «S» e a sensação $S$. Ora uma recordação da conexão entre o nome «S» e a sensação $S$ só pode ser considerada como sendo a recordação certa quando o conteúdo da recordação está de acordo com o meu segundo passo na construção de «S», nomeadamente que «S» é de facto o nome de $S$. Portanto estamos agora diante da questão de saber como é que no futuro se poderá decidir se o meu emprego de $« S »$ como nome de $S$ é de facto justificado; por outras palavras, precisamos de encontrar um critério que nos permita separar aqueles empregos de «S», que estão de acordo com o segundo passo já referido, daqueles que não estão.

No parágrafo 258 de Philosophische Untersuchungen recusa Wittgenstein a ideia de que este critério me pode ser dado através da consideração daquilo que no futuro me aparecer como sendo a recordação certa da construção de «S» uma vez que aquilo que no futuro me aparece como sendo a recordação certa não é ainda critério para decidir se a recordação é ou não a recordação certa. Ora, por outro lado, a hipótese da possibilidade da construção privada de «S» implica a existência de um tal critério. Assim ao demonstrarmos a inexistência do critério refutamos a possibilidade da construção privada de «S».

Para compreender a natureza do argumento de Wittgenstein convém ter em mente uma sinóptica da construção de «S» como protótipo da construção de $L_{p}$ : 
i) A concentração da atenção em $S$;

ii) A atribuição a $S$ do seu nome;

iii) A fixação na memória de que «S»é o nome da sensação $S$.

Deste modo, as regras que são usadas na construção de «S» e de $L_{p}$, são o que se pode designar, neste contexto, por regras privadas, no sentido de privacidade de posse e de privacidade epistemológica e assim as regras só podem ser possuídas por mim e só eu posso saber como as regras são usadas de facto nas diversas construções que levam à formação de $L_{p}$. Mas tal como a minha impressão de que o meu uso do nome «S» é o uso do nome certo de $S$ não chega para fazer desta impressão um critério, assim também a noção de uma regra privada, no sentido especificado, não é suficientemente clara para a poder distinguir de uma impressão, i.e., não posso inferir a existência de uma regra do facto de me julgar a seguir uma regra. Quando me encontro de baixo da impressão, digamos durante a construção de «S», de seguir uma regra para poder prosseguir a construção, não tenho ainda suficiente evidência para me permitir deduzir a existência de uma regra. Para me ser me permitida esta inferência tenho que ser capaz de encontrar, para a minha impressão, uma justificação independente dela que tenha o poder de lhe conferir validade intersubjectiva. Na construção de «S» no entanto a justificação da validade dos passos permanece apenas subjectiva, uma vez que a minha impressão do emprego de «S» ser o emprego do nome certo de $S$ só pode, por sua vez, ser justificado por uma outra impressão. Este processo de justificação de uma impressão através do apelo a uma outra impressão conduz à falácia conhecida pela designação de regressus ad infinitum ${ }^{8}$. Logo uma regra privada, e portanto a impressão de seguir uma regra, não é uma regra. Ora como vimos no capítulo anterior uma linguagem ou um jogo de linguagem é definido pelas suas regras. Assim uma «linguagem privada» é uma impossibilidade lógica.

Terminamos esta secção fazendo referência a uma estratégia a propor como um meio de escapar à reductio ad absurdum de Wittgenstein e por último à refutação desta estratégia com os termos da reductio que acabamos de expor. A estratégia proposta consiste em tentar reganhar para o conceito de seguir uma regra privada o estatuto que este con-

\footnotetext{
${ }^{8}$ Uma formulação extremamente elegante desta interpretação do argumento de Wittgenstein aqui proposta é a de Hintikka, Jakko, na sua nota «Wittgenstein on Private Language: Some Sources of Misunderstanding» in Mind, 78, 1969, pp. 423-425.
} 
ceito perdeu com o argumento de Wittgenstein, uma vez que se o conceito puder ser reintroduzido a possibilidade de construção de uma linguagem como $L_{p}$ fica de novo assegurada.

Assim, começamos por admitir que não me é possível nunca saber se sigo as regras de minha linguagem $L_{p}$ de facto ou se apenas me imagino que as sigo, dado que não me é possível construir uma demonstração de que as sigo efectivamente. Mas em vez de construir uma demonstração de que sigo as regras de uma linguagem $L_{p}$ efectivamente, posso mostrar que as sigo ao mostrar que me recordo do sentido certo do nome « $S$ » ou, por outras palavras, ao mostrar que tenho dele a recordação certa. Esta acomodação é perfeitamente razoável e uma vez concedida é suficiente para reintroduzir a noção de uma regra privada e com ela a possibilidade de construir $L_{p}$.

A refutação desta proposta consiste em observar que a única razão pela qual eu julgo poder associar com o conceito de seguir uma regra privada um conteúdo fixo é o facto de eu associar com ele não este conteúdo mas imagens mentais de diversas formas que aparentam dar ao conceito o conteúdo que carece. Mas, como já foi estabelecido no Capítulo 1 de Espontaneidade da Razão, na formulação do sentido de uma expressão como «S» em termos das imagens mentais com ela associadas, estas imagens por sua vez carecem tanto de sentido como as expressões que elas supostamente são introduzidas para explicar. Em particular, não está ainda de todo determinado como é que estas imagens por sua vez se usam, i.e., que critérios se adoptam para regular o seu uso de modo que a questão não é resolvida mas apenas deslocada ${ }^{9}$. Finalmente resta observar que quando eu digo que posso encontrar a minha recordação do que foi a sensação $S$ e do seu nome «S», podendo assim justificar o meu emprego de «S» em circunstâncias futuras, tenho também que incluir que a recordação em questão tem que ser a recordação certa visto que nenhuma outra serve para realizar a justificação desejada. Mas, como já foi demonstrado durante a reductio ad absurdum, não estamos em condições de poder especificar um critério que nos permita analisar estas recordações de modo a poder decidir quando é que uma recordação é a recordação certa. Os critérios que apelam para as minhas impressões não servem para o processo de decisão e assim, na ausência de qualquer critério, deixa

\footnotetext{
${ }^{9}$ Acerca do papel de Vorstellungen, no texto referido pelo termo imagens mentais, ver a análoga refutação do seu uso em «Widerlegung des Idealismus» in Kritik der Reinen Vernunft, Elementarlehre, II T. 1 Ab. II Buch 2 Hauptst.
} 
de me ser possível falar de minha recordação de «S» como sendo a recordação certa.

Uma variante elegante desta estratégia consiste em argumentar que embora seja possível que eu não consiga oferecer um critério que justifique uma decisão acerca de eu ter ou não seguido uma regra privada, pode no entanto uma terceira pessoa estabelecer se eu segui ou não uma regra, nomeadamente verificando se o meu emprego do nome «S» é determinado pela ocorrência da mesma sensação $S$.

A refutação desta variante consiste na análise da noção de «mesma sensação» ou, o que é o mesmo, na análise do critério de identidade a ser usado a propósito de qualquer par de sensações considerado. De novo temos que fazer apelo às noções introduzidas no Capítulo 1 de Espontaneidade da Razão, em particular, à noção de que o sentido de um conceito, como «identidade entre sensações» não é introduzido uma vez por todas mas, ao contrário, é estabelecido gradualmente através das diversas estipulações acerca de seu emprego.

Vale a pena considerar neste momento um exemplo conhecido de Wittgenstein, usado normalmente em discussões acerca da natureza da necessidade lógica e à qual voltaremos com mais pormenor no decorrer do Capítulo 3 de Espontaneidade da Razão. O exemplo revolve à volta da noção da aquisição do conceito de sucessor de um número inteiro $n$, onde se supõe que uma pessoa compreendeu o método de determinar o sucessor de um número inteiro $n$, nomeadamente ao ter compreendido o sentido de $« n+1$, para qualquer $n »$. Esta suposição é a seguir confirmada pelo facto de em diversas ocasiões a pessoa em questão formar sempre correctamente o sucessor do número inteiro dado. No exemplo de Wittgenstein passamos agora a considerar o facto surpreendente que esta compreensão do método de formar o sucessor de um número inteiro $n$ só é satisfeita quando o número é menor do que, por exemplo, 1 000. Quando n é maior do que 1000 já não é derivável de «n +1 , para qualquer $n »$. Em particular uma variedade de métodos parece ser agora o caso. Assim, quando $n$ é maior do que 1000 e menor do que 2000 , a formação do sucessor é agora $n+2$, quando $n$ é maior do que 2000 e menor do que 3000 , o sucessor de $n$ é calculado como sendo $n+3$.

Segundo Wittgenstein este comportamento não é irracional e é até justificável uma vez que não existe nada na primitiva instrução do método de calcular o sucessor de um número inteiro $n$ que exclua a possibilidade de se proceder de acordo com a variedade de métodos a que o exemplo se refere. Em particular, a situação não é sequer 
esclarecida através de uma nova ordem, novamente a ordem de proceder da mesma maneira, i.e., da maneira usada no cálculo do sucessor de $n$ para $n$ menor do que 1000 , uma vez que é sempre possível responder-se que se está ainda a proceder da mesma maneira. Chegamos assim a compreender a noção proposta por Wittgenstein segundo a qual se deve reconhecer que o conceito de «identidade entre dois métodos» não é definido de uma vez por todas mas tem que ser estabelecido gradualmente e que, em circunstâncias diferentes, serão propostos critérios diferentes. No caso de uma regra será então também gradualmente determinado se a regra foi ou não seguida da mesma maneira e a determinação do facto de se ter seguido a regra correctamente reduz-se à determinação do procedimento estar ou não de acordo com o uso comum. Vale a pena reparar no facto de as circunstâncias do exemplo não serem normalmente encontradas na experiência, serem de natureza puramente contingente e não necessárias uma vez que, como já foi dito, a primitiva instrução não exclui necessariamente a possibilidade de se adoptar a variedade de métodos.

A resistência que normalmente se oferece à adopção da crítica implícita no exemplo de Wittgenstein é causada pelo facto de nos julgarmos de posse de uma ideia clara e inequívoca de identidade, cujo paradigma é normalmente expresso pela primeira das leis de Leibniz, i.e., o axioma da identidade segundo o qual qualquer objecto é idêntico a si próprio. Mas, como é conhecido, para definirmos o conceito de identidade este axioma tem que ser suplementado por outro que especifique como condição necessária de identidade, a possibilidade de se atribuírem os mesmos predicados a objectos considerados idênticos. No caso da nossa discussão da existência possível de uma linguagem privada podemos agora formular a tese crucial, em parte já obtida no Capítulo 1 de Espontaneidade da Razão, segundo a qual seguir uma regra é em si um costume. Só onde se verifica a existência de um uso comum e que obrigue igualmente todos os utentes de uma expressão se pode falar no estabelecimento de um critério para o emprego correcto da expressão, e portanto da formação de uma regra que controle esse emprego. Na circunstância de eu me dizer a mim próprio que na minha linguagem privada sempre que ocorre de novo a sensação $S$ eu usarei o nome «S» não tenho ainda uma regra para o uso correcto de «S», uma vez que eu posso fazer com o nome $\langle S »$ o que eu quiser sem necessariamente contradizer a minha determinação uma vez que, na ausência de uma instância independente de mim próprio, eu posso sempre chamar mais tarde a mesma sensação ao que 
eu quiser. Deste modo chegamos assim a um resultado análogo ao da nossa análise da determinação da recordação correcta, nomeadamente de que se eu posso chamar «o mesmo» àquilo que eu quiser, o uso desta noção torna-se por esse mesmo facto irrelevante e tem que por isso considerar-se a noção assim definida como vazia ${ }^{10}$.

\section{A refutação do solipsismo}

O nosso propósito nesta secção é analisar o género de argumentos que, partindo da premissa da existência de uma linguagem privada como $L_{p}$, conduzem à conclusão da minha impossibilidade de acesso aos estados mentais de outrem. Com efeito, se eu garanto a existência da minha linguagem privada $L_{p}$, garanto igualmente, pelo mesmo raciocínio a existência da linguagem privada $L_{p}^{\prime}$ de Job. A consequência imediata desta admissão da hipótese da linguagem privada é que eu falo a minha linguagem privada $L_{p}$ e Job fala a sua linguagem privada $L_{p}^{\prime}$, eu atribuo o meu sentido em $L_{p}$ à palavra «dor» e Job atribui o seu sentido em $L_{p}^{\prime}$ à palavra «dor», de modo que a minha única esperança de saber e de compreender o que Job quer dizer quando fala acerca de dor é transferir para o caso de Job aquilo que eu sei acerca do meu próprio caso quando utilizo a palavra «dor».

Esta transferência da minha própria experiência para a experiência de Job é justificada como sendo uma inferência per analogiam de tal modo que não me resta senão dizer que, como consequência do uso das nossas linguagens privadas, o meu conhecimento e a minha compreensão da experiência de dor de Job tem apenas um carácter analógico $^{11}$. Assim a tese a refutar tem a forma de uma proposição condicional, o antecedente da qual é a existência possível ou presumida de uma linguagem privada e o consequente da qual é a natureza analógica do meu conhecimento dos estados de consciência de outrem. O nosso propósito é agora expor os argumentos que Wittgenstein aduz contra

${ }^{10}$ A mais conhecida tentativa de refutação do argumento de Wittgenstein aqui apresentado é a de Castañeda, Hector Neri «The Private Language Argument as a reductio ad absurdum» in The Private Language Argument, org. O. R. Jones, 1971, pp. 132 e segs.

${ }^{11}$ A tese de Wittgenstein representada no texto é o objecto do ensaio de Malcolm, Norman, «Knowledge of Other Minds» in Knowledge and Certainty: Essays and Lectures, Englewood Cliffs, New Jersey, 1963, pp. 130-140. 
a natureza analógica deste conhecimento e desta maneira dar-nos a possibilidade de obter, por modus tollens, uma nova refutação da existência possível de uma linguagem privada como $L_{p}$.

Convém in limine regressar à formulação adoptada acima, nomeadamente de que sob a admissão da hipótese da existência de uma linguagem privada como $L_{p}$, o meu conhecimento e a minha compreensão dos estados de consciência de outrem é de natureza puramente analógica. Com efeito podemos aqui distinguir de facto duas proposições diferentes:

i) A natureza do meu conhecimento dos estados de consciência de outrem é puramente analógica; $\mathrm{e}$

ii) É para mim destituído de sentido falar acerca dos estados de consciência de outrem.

É fácil de ver que a proposição ii é mais forte de que a proposição i no sentido que ii é condição suficiente de i uma vez que não posso sequer falar acerca da natureza do meu conhecimento dos estados de consciência de outrem, sem ter previamente uma ideia acerca do sentido das expressões que terão que ser empregues na descrição dos estados de consciência de outrem. Assim, a nossa intenção é agora proporcionar a análise da proposição ii e a partir dela estabelecer a conclusão desejada, nomeadamente de que não existe conhecimento analógico dos estados de consciências de outrem.

A primeira linha da argumentação que utilizamos é a do parágrafo 320 de Philosophische Untersuchungen, a qual consiste essencialmente em impedir a pretensão de analogicamente transferir para a experiência de dor de Job aquilo que foi ou é a minha própria experiência de dor. De facto se eu só posso chegar a compreender em que é que consiste a experiência de dor de Job a partir do modelo da minha própria experiência de dor, a questão surge como é que de facto a transferência se processa, uma vez que consiste em transferir a dor que de facto eu sinto para uma dor que de facto eu não posso sequer sentir. É relevante reparar que a transferência que se propõe que seja efectuada não é analógica no sentindo de ser o género de transferência que normalmente eu consigo fazer na minha imaginação de transferir a sensação de dor, ocasionada por uma dor de ouvidos, para a sensação de dor, ocasionada por uma dor de dentes. No caso da transferência proposta eu não chego sequer a ter a dor que me proponho a transferir, uma vez que a dor é a dor de Job a que eu, ex hypothesi, não 
tenho acesso directo. Não posso assim pois obter na minha imaginação as imagens mentais associadas com a dor de Job. Logo, se o sentido da palavra «dor» na minha linguagem $L_{p}$ é estabelecido apenas por referência à minha percepção da minha própria dor, a própria palavra «dor» terá apenas o significado de designar a minha experiência privada de dor a que só eu posso ter acesso. Pela mesma razão serme-á também impossível poder falar acerca da experiência de dor de Job, uma vez que a palavra «dor» designa apenas na minha linguagem $L_{p}$ a minha experiência privada de dor, ser-me-á impossível compreender o sentido da própria concepção de dor de Job.

Uma outra forma de argumentar a favor da concepção analógica acerca do meu conhecimento dos estados de consciência de outrem é recorrendo ao conceito, já utilizado anteriormente, de identidade. Durante a argumentação a favor da linguagem $L_{p}$ apela-se, como foi então desenvolvido, para a identidade entre as sensações de dor que ocorrem em instantes, digamos $\mathrm{I}_{1}$ e $\mathrm{I}_{2},{ }^{12}$ a fim de justificar o emprego da mesma expressão em instantes diferentes. Uma variante desta concepção pode ser utilizada relativamente ao problema sob análise, nomeadamente apelando para a identidade das experiências de que eu e Job somos os sujeitos, no sentido em que eu me proponho agora a afirmar que a minha suposição de que Job tem uma experiência de dor é justificada pelo facto de eu com ela supor que Job tem o mesmo que eu tenho, quando tenho a experiência de dor.

Wittgenstein rejeita este uso do conceito de identidade para estabelecer a tese da natureza analógica do meu conhecimento dos estados de consciência de Job. É evidentemente claro que se eu tenho a experiência de dor e se Job tem a experiência de dor então é perfeitamente correcto afirmar-se que eu e Job temos a mesma coisa, nomeadamente a experiência de dor. Mas aqui supõe-se ter-se estabelecido independente e anteriormente cada um dos termos da conjunção, i.e., de que eu tenho a experiência de dor e que Job tem a experiência de dor e assim, a esta luz, a asserção da conjunção é completamente justificada. Todavia, no argumento agora proposto, conclui-se que eu e Job temos a mesma coisa sem ter havido previamente uma estipulação das condições debaixo das quais eu e Job seremos considerados como tendo a mesma experiência. Wittgenstein estabelece este ponto por intermédio do exemplo célebre da determinação da hora na Terra e no Sol, no

\footnotetext{
${ }^{12}$ Em outros pontos do texto referidos pela notação $t, k, t \cup k$.
} 
parágrafo 350 de Philosophische Untersuchungen. Assim é perfeitamente claro o que eu digo quando afirmo que quando é na Terra meia-noite e no Sol meia-noite estou então justificado em afirmar que é a mesma hora na Terra e no Sol. Mas evidentemente na ausência de um critério ${ }^{13}$ para estabelecer as condições debaixo das quais se considerará que é a mesma hora na Terra e no Sol, a minha asserção que é no Sol a mesma hora que na Terra, i.e., meia-noite quando na Terra é meia-noite, permanece sem justificação e sem sentido.

Terminamos esta seç̧ão mostrando com mais detalhe como o recurso à noção de identidade não estabelece a pretensão da tese da natureza analógica do meu conhecimento dos estados de consciência de outrem. Trata-se agora de usar a sugestão do parágrafo 250 de Philosophische Untersuchungen e ver em que condições é que se pode propor estabelecer a identidade entre os predicados $D\left(x_{i}\right)^{14}$ quando aplicados a mim e a Job. Como já foi indicado a questão revolve à volta do facto de a conjunção «eu tenho $D$ e Job tem $D$ » ter a sua asserção justificada quando já foi previamente decidido em que é que consiste a justificação de cada um dos conjuntos. O que não está justificado é o argumento que consiste em definir $D\left(x_{i}\right)$ em termos de um indivíduo, nomeadamente eu, e a seguir pretender estabelecer o sentido da expressão «Job tem dor» afirmando que se trata do mesmo predicado $D$ que se usou na definição de «eu tenho $D$ ». Logo, se $D\left(x_{i}\right)$ só pode ser definido em termos de um indivíduo, a sua aplicação a um outro indivíduo não pode ser feita sem se justificar a identidade do novo indivíduo e portanto o apelo para a identidade do predicado tem que ser considerado como irrelevante. A não ser assim, dever-me-ia ser então possível empregar, por exemplo, a expressão «a lua tem dor», e justificá-la dizendo que a lua tem o mesmo que eu tenho, nomeadamente dor. Portanto, se só me é possível estabelecer o sentido da palavra «dor» pela consideração da minha experiência privada de dor, a sua transferência para o caso da lua não pode ser feita apenas dizendo que a lua tem o mesmo que eu tenho. Logo a questão não é resolvida pelo simples recurso à identidade do predica-

\footnotetext{
${ }^{13} \mathrm{O}$ sentido do termo critério como o par $\left\langle K_{i}, P>\right.$ necessário para estabelecer a identidade entre os dois termos da conjunção é adequadamente definido na p. 87 e segs. de Espontaneidade da Razão.

${ }^{14}$ A ideia geral de que ao ser humano $x_{i}$ é atribuído o predicado «ter dor» é aqui representada na notação usual $D\left(x_{i}\right)$.
} 
do. Não estamos assim de posse de um critério que nos permita estabelecer as condições debaixo das quais se considera que o mesmo predicado pode ser aplicado, e à falta deste critério se reduz a falta de sentido da pretensão da tese analógica do meu conhecimento acerca dos estados de consciência de outrem.

\section{A refutação da tese da inserção subsequente de $L_{p}$ em $L$}

Dois novos aspectos do nosso problema acerca da natureza do conhecimento dos estados de consciência de outrem constituirão o objecto das considerações a desenvolver neste parágrafo, nomeadamente a questão que se refere à determinação do lugar da experiência interior como fundamento da lógica das expressões usadas acerca de sensações, como a sensação de dor e ainda a determinação do lugar da experiência interior como fundamento do grau de conhecimento que é possível alcançar acerca dos estados de consciência de outrem. Em particular, a nossa primeira questão pode ser mais dramaticamente expressa pela determinação do grau de prioridade da linguagem $L_{p} \mathrm{em}$ relação a uma linguagem intersubjectiva a que chamaremos $L$. Partindo da premissa da existência assumida de $L_{p}$ parece ser plausível argumentar que o sentido de uma expressão de $L$ é função do sentido da mesma expressão em $L_{p}$ e que é portanto a inserção subsequente de $L_{p}$ em $L$ que constitui $L$.

Com efeito, segundo a concepção da inserção subsequente de $L_{p}$ em $L$, a palavra «dor» adquire para mim o seu sentido na medida em que eu a concebo como o nome geral de uma experiência, à concepção da qual eu só chego através da operação de abstracção ${ }^{15}$ efectuada sobre minhas próprias experiências de dor, e por isso é que só em sentido puramente analógico eu consigo chegar a compreender em que é que consiste a experiência de dor de Job. A nossa questão consiste agora pois em estabelecer se esta operação nos proporciona o processo que precisamos para compreendermos o sentido da palavra «dor» em $L$, i.e., na linguagem suposta ser intersubjectiva. Por um lado, como se pode deduzir dos resultados do capítulo anterior, a palavra «dor» é apenas uma das partes constituintes do jogo de linguagem acerca de dor e da sua expressão, de modo que o simples uso

\footnotetext{
${ }^{15}$ No sentido acima referido em que o termo «dor» é entendido como o predicado $D\left(x_{i}\right)$.
} 
desta palavra em si não é suficiente para estabelecer se estou ou não de posse do jogo de linguagem em questão. Mas além desta uma questão mais fundamental é agora posta à nossa consideração, nomeadamente que a justificação da inserção de $L_{p} \mathrm{em} L$ não foi ainda oferecida de modo a ser esclarecido o desejado processo de transferência, a efectuar na minha consciência, do sentido da palavra «dor», sugerido pela minha própria experiência, para a experiência de outrem. Esta transferência parece prima facie relativamente simples de conceber e assim de ser justificada, uma vez que eu e Job usamos a palavra «dor» e para cada um de nós parece que a palavra adquire o seu sentido por estar imediatamente associada com a experiência que eu (respectivamente nós) tenho (respectivamente temos) de dor, de tal modo que a ela devem estar associadas as diversas imagens mentais que subsequentemente representam a experiência de dor.

Aceite esta interpretação não se pode no entanto deixar de ser levado a encarar a questão da possibilidade de Job ter da experiência de dor uma experiência qualitativamente diferente da minha, e portanto a dúvida acerca da relação da palavra «dor» e a experiência de dor torna-se legítima, no sentido em que eu não pareço ter meios de saber se falamos acerca da mesma experiência quando ambos usamos a palavra «dor». Como não me é possível entrar na consciência de Job a fim de poder determinar com completa segurança que género de experiência é que Job tem, quando tem a experiência a que ele chama «dor», não me resta, nesta introspecção, senão estipular que todos os utentes da linguagem chamem precisamente sempre «dor» à mesma sensação. No entanto, à luz da interpretação proposta, eu só posso chegar a ter conhecimento do sentido da palavra «dor» através da consideração da minha própria experiência de dor, e é portanto agora possível que aquilo a que eu acabo de chamar «dor» seja qualitativamente diferente daquilo que Job chama pelo mesmo nome.

Não é agora possível calar esta dúvida, i.e., a dúvida acerca da identidade do que e Job temos quando ambos usamos a palavra «dor», dizendo que seja como for temos ambos pelo menos qualquer coisa a que estamos dispostos a chamar «dor», uma vez que, ex hypothesi, esta qualquer coisa que ambos temos é presumivelmente também privada, no sentido em que foi estabelecido o emprego deste termo nos pará- 
grafos anteriores, e assim volta a ser possível que o que ambos temos seja diferente ${ }^{16}$.

Concluímos assim que a nossa hipótese de que o sentido de uma expressão de $L$ depende do sentido da expressão em $L_{p}$, após a inserção subsequente de $L_{p}$ em $L$, representa um desvio das estipulações apresentadas no Capítulo 1 de Espontaneidade da Razão acerca da aquisição da competência linguística através de jogos de linguagem, no nosso caso num jogo de linguagem acerca do emprego da palavra «dor». De facto, como vimos então, é devido à circunstância de as palavras que se referem às experiências da consciência pertencerem $a b$ initio a $L$, que se consegue falar acerca destas experiências em $L$. Logo a inserção subsequente de $L_{p}$ em $L$ não pode ser o que constitui o sentido de uma expressão em $L$.

Wittgenstein cristalizou estas considerações na conhecida imagem do parágrafo 293 de Philosophische Untersuchungen. Aqui supõe-se, para efectuar a comparação, que eu e Job temos cada um uma caixa dentro da qual está algo a que ambos chamamos «escaravelho». Eu não estou em condições de ver a caixa de Job e Job não está em condições de poder ver a minha caixa. Assim agora cada um de nós sente-se justificado em afirmar que o sentido da palavra «escaravelho» é estabelecido para cada um de nós apenas pela observação do seu próprio escaravelho. Mas neste caso, uma vez que o sentido da palavra «escaravelho»é estabelecido apenas pela consideração do meu próprio «escaravelho», eu posso chamar «escaravelho» ao que quiser; em particular a minha caixa pode conter um polvo em vez de um escaravelho, ou o que eu tenho na caixa é um objecto em transformação, ou simplesmente a caixa está vazia no momento. Se na nossa linguagem $L$ a palavra «escaravelho» tem um emprego determinado, não pode este emprego ser concebido como sendo o nome do objecto dentro da minha caixa. Este objecto é irrelevante para o género de afirmações que eu me encontro a fazer e portanto, segundo Wittgenstein, não está incluído neste jogo de linguagem - a caixa até pode estar, como já foi mencionado, vazia. Como é óbvio a caixa representa a consciência e o escaravelho a sensação de dor, tal como são representadas na doutrina na concepção analógica do meu conhecimento acerca dos estados de consciência de outrem. A imagem (do escaravelho na caixa ou) da

\footnotetext{
${ }^{16}$ Cf. Malcolm, Norman, «Wittgenstein's Philosophical Investigations» in Knowledge and Certainty: Essays and Lectures, Englewood Cliffs, New Jersey, 1963, pp. 96-129.
} 
natureza privada dos objectos da minha consciência recebe o seu poder de atracção de principalmente duas fontes: a já mencionada falácia da analogia e a doutrina, também já mencionada, acerca da natureza da linguagem segundo a qual a função essencial desta é a função de nomear.

Quanto à primeira resta-nos observar que aqui a falácia da analogia consiste em tentar transferir para o universo da consciência as formas de representação usadas no universo sensível, nomeadamente a análise deste em termos de objectos e de processos. Assim deve-me ser possível encontrar na minha consciência os objectos e processos que possibilitarão a sua análise e que proporcionarão a desejada referência para as expressões $L$, as quais podem ser interpretadas como asserções acerca da consciência. Quanto à segunda destas fontes, apelamos uma vez mais para os resultados do Capítulo 1 de Espontaneidade da Razão e para a crítica de Wittgenstein ao que ele chamou de alimentar o pensamento à custa de uma dieta unilateral. Não nos resta pois senão recordar que, se se interpreta a função da linguagem à luz de uma função única de designar objectos do chamado mundo exterior, então torna-se irrelevante procurar distinguir entre as diversas categorias de objectos assim designados, obtendo-se assim a mesma interpretação do funcionamento da linguagem considerando objectos em si tão diferentes como dores, números, cores ou direcções. Assim se interpretamos a natureza lógica das expressões que utilizamos para falar acerca de sensações à luz do modelo único de designação e objecto, a consideração do objecto neste género de expressões torna-se irrelevante.

Voltamo-nos agora para a segunda das nossas questões, nomeadamente a questão acerca do lugar da experiência interior na determinação do grau de conhecimento que eu posso ter acerca da consciência de outrem, em particular no que se refere à inacessibilidade dos estados de consciência de outrem. Wittgenstein dramatizou com sugestivo realismo a natureza desta inacessibilidade nas suas diversas discussões acerca do princípio do terceiro excluído. Assim para eu poder pretender afirmar com sentido que «ou existe um número inteiro com a propriedade $P$ ou tal número não existe» eu tenho que supor, para aceitar a verdade da minha declaração, a existência de uma consciência essencialmente diferente da minha, nomeadamente uma consciência infinita, que tem a percepção simultânea da totalidade dos números inteiros, e que à luz desta percepção pode decidir qual é o número inteiro com a propriedade desejada, ou então que não existe na totalidade dos números inteiros um número com a 
propriedade desejada. Uma pretensão idêntica acerca dos poderes da minha percepção parece também encontrar-se na minha declaração «ou Job tem a sensação de dor ou Job não tem a sensação de dor» onde de novo eu tenho que supor uma extensão dos poderes da minha percepção, a qual não me é normalmente dada na experiência, se quero afirmar que a minha disjunção tem um sentido determinado. Mas em ambos os casos, como Wittgenstein indica no parágrafo 352 de Philosophische Untersuchungen, embora o sentido das minhas declarações pareça estar estabelecido inequivocamente, esta determinação de sentido depende essencialmente de metáforas acerca da acessibilidade dos objectos do pensamento, no primeiro caso na percepção simultânea da infinitude da totalidade dos números inteiros e, no segundo, na percepção dos objectos da consciência de Job. Em vista destas circunstâncias parece então razoável argumentar a favor da natureza analógica do meu conhecimento dos estados de consciência de outrem, nomeadamente usando o facto do aparente contraste entre o grau de conhecimento alcançado: enquanto que eu posso saber de mim próprio se tenho ou não uma experiência de dor, acerca de Job não posso mais do que supor que ele tem a experiência de dor.

Contra esta forma de argumentação começa Wittgenstein por observar que, compreendendo o termo «saber» tal como é normalmente empregue, é um facto da experiência que eu sei se ou quando Job está a ter uma experiência de dor, e portanto as alegadas dificuldades e graduações epistemológicas acerca da natureza deste conhecimento só podem ser devidas a um desvio do sentido do termo tal como é normalmente empregue. Por isso a relacionada pretensão de que Job não pode saber acerca de mim se eu tenho a sensação de dor com a certeza de que só eu posso ter, é igualmente rejeitada à luz da interpretação anterior do termo «saber». A esta luz reconhece-se que não faz sentido tentar dizer de mim que eu sei que tenho a sensação de dor uma vez que, neste sentido, o meu saber que tenho a sensação de dor se reduz ao simples facto de eu ter a sensação de dor.

De facto a tese da natureza analógica do meu conhecimento dos estados de consciência de outrem consiste, como vimos, em manter que a palavra «dor» é o nome de uma determinada experiência interior, nomeadamente a ocorrência da sensação de dor na minha consciência, à qual ninguém, a não ser eu próprio, pode ter qualquer acesso. Assim quando Job diz de si próprio que tem a experiência de dor, é esta experiência, que eu conheço do meu próprio caso, que é o sentido desta declaração. Quando Job, por sua vez, diz de mim que 
eu tenho a experiência de dor, quer com isso dizer que eu tenho na minha consciência a ocorrência do mesmo género de sensação que ele tem quando fala das suas experiências de dor. Logo, no meu caso, o meu conhecimento da minha sensação de dor é um dado imediato da consciência e, como não posso ter acesso à consciência de Job, não posso alcançar mais, acerca do que se passa na sua consciência, do que uma conjectura.

O que Wittgenstein rejeita nesta resposta é que se a suposição fosse aceite de que só acerca de mim próprio é que posso saber se tenho ou não a sensação de dor e que acerca de Job não posso fazer mais do que uma conjectura, então o emprego do termo «saber» sofreu uma modificação que não foi legitimada na argumentação proposta no argumento por analogia, uma vez que, no sentido aceite, é normalmente um facto da experiência que eu sei com relativa segurança quando Job tem uma sensação de dor e quão destituído de sentido se me apresenta a noção de eu saber acerca de mim próprio que tenho a sensação de dor.

\section{A eliminabilidade de expressões de autoconhecimento}

As considerações que até aqui representámos acerca da natureza da experiência interior não são por si suficientes para conduzirem a uma decisão acerca de um problema tradicional da filosofia da consciência, nomeadamente o problema do dualismo psicossomático, i.e., a partição do mundo da experiência em consciência e realidade, ou corpo e espírito ou sujeito e objecto. Embora Wittgenstein não aborde estas questões na sua formulação tradicional, a sua doutrina acerca destas questões pode no entanto ser deduzida das suas considerações acerca da estrutura geral que estas questões apresentam em comum. Trata-se nelas, de facto, de determinar as relações recíprocas entre o mundo interior e o mundo da experiência fenomenal o que, do ponto de vista de Wittgenstein, consiste em determinar o sentido das expressões que se referem, na linguagem corrente, às experiências interiores. A cada uma destas expressões que, na linguagem corrente, representa uma destas experiências, chama Wittgenstein uma exteriorização ${ }^{17}$.

\footnotetext{
${ }^{17}$ Acerca da relação entre este problema e o problema tradicional ver Hacker. P. M. S. «A Cloud of Philosophy Condensed into a Drop of Grammar» in Insight and Illusion, Clarendon Press, Oxford, 1972, pp. 252 e segs.
} 
Assim, uma exteriorização é uma declaração feita por mim de que uma dada experiência interior está a decorrer, um exemplo típico de uma exteriorização é minha declaração «dói-me a cabeça» ou qualquer das suas variantes, como «tenho uma dor de cabeça». O problema com que nos defrontamos agora é o de tentar elucidar a natureza lógica destas expressões; em particular queremos nesta secção expor a doutrina de Wittgenstein acerca da natureza lógica das exteriorizações sob uma forma que conduza a uma decisão acerca do problema tradicional mencionado acima. Finalmente teremos que determinar a posição relativa desta doutrina em relação ao argumento já apresentado contra a existência de uma linguagem privada.

A doutrina de Wittgenstein deixa-se formular sucintamente na seguinte proposição: uma exteriorização não é uma proposição e, assim, o principio do terceiro excluído não se lhe aplica. Mas o que não pode ser verdadeiro nem falso também não pode ser objecto de conhecimento. Logo que é representado na exteriorização é incognoscível. Por isso não tem sentido pretender afirmar «eu sei que tenho uma dor de cabeça». Deste modo pretende Wittgenstein reduzir o conhecimento que eu afirmo que tenho acerca de minha dor à própria dor. Chegamos assim à conclusão que o conhecimento que eu tenho acerca dos meus estados de consciência não é uma parte essencial da minha explicação do sentido das expressões em que eu afirmo conhecer os meus estados de consciência, e por isso eliminável da minha explicação do sentido dessas expressões.

Para expor esta nova tese, a que chamaremos a tese acerca da eliminabilidade da expressão de autoconhecimento ${ }^{18}$, começaremos por regressar ao ponto já alcançado anteriormente, de que rejeitada a existência da linguagem $L_{p}$ só faz sentido falar acerca da linguagem intersubjectiva $L$, em relação à qual consideramos como estabelecido in limine o segmento de $L$ que se refere às sensações. Este segmento, à luz do argumento aduzido contra a existência de $L_{p}$ não é estabelecido como uma parte de $L$ cuja função é descrever as ocorrências de sensações na minha consciência mas antes, ao contrário, a concepção destas sensações só me é acessível através da aquisição da linguagem $L$. Por outro lado, como podemos deduzir de um dos nossos resultados da Teoria do Sentido, não podemos esperar que o termo «dor» tenha o

\footnotetext{
${ }^{18}$ Prefixos como «eu sei que» podem ser designados por operadores epistémicos, e a tese de Wittgenstein é pois que operadores epistémicos, aplicados a descrições de estados de consciência, se reduzem aos próprios estados de consciência.
} 
mesmo sentido, e portanto a mesma forma de aplicação, em sentido absoluto. Como foi então proposto, este termo terá também que ser contextualmente relativizado. Wittgenstein distingue dois contextos que determinam duas formas essencialmente diferentes da aplicação, e portanto do sentido, de um termo como «dor», nomeadamente o contexto em que o termo ocorre como predicado de uma proposição cujo sujeito é a primeira pessoa do presente do indicativo, e um outro contexto em que o termo ocorre como predicado numa proposição cujo sujeito é a terceira pessoa do presente do indicativo.

A tese acerca da eliminabilidade da expressão acerca do autoconhecimento depende de uma premissa geral que é agora útil formular: aquilo de que eu não posso duvidar também não posso ter a certeza e aquilo de que não posso ter a certeza também não posso conhecer. À luz desta premissa podemos agora propor a generalização de uma ideia já anteriormente mencionada acerca da eliminabilidade do prefixo «eu sei que» quando é aposto a uma exteriorização. Considerando um exemplo já mencionado, «eu tenho uma dor de cabeça»o resultado de prefixar «eu sei que» é a aparente proposição «eu sei que eu tenho uma dor de cabeça». Mas agora a expressão do meu conhecimento, tal como a expressão da minha dúvida, torna-se destituída de sentido, uma vez que aquilo de que não faz sentido eu duvidar também não faz sentido eu pretender ter conhecimento. Não é esse obviamente o caso quando o termo «eu» em «eu tenho uma dor de cabeça» é substituído por «ele». Eu posso perfeitamente afirmar «eu sei que ele tem uma dor de cabeça» como também posso perfeitamente afirmar «eu duvido que ele tenha uma dor de cabeça»; analogamente, o desejo de conhecer é tratado nesta análise do mesmo modo, e assim faz sentido afirmar «eu gostaria de saber se ele tem uma dor de cabeça» e não faz sentido afirmar «eu gostaria de saber se eu tenho uma dor de cabeça». O mesmo género de análise pode ainda ser aplicado a designações temporais, de tal modo que faz sentido eu dizer «eu sei que ontem tive uma dor de cabeça» e já não faz sentido eu dizer «eu sei que agora tenho uma dor de cabeça».

Embora seja possível dividir as exteriorizações que são expressas na primeira pessoa do presente quanto à sua função em duas classes principais, aquelas cuja função é comunicar descritivamente o conteúdo de uma experiência interior e aquelas cuja função é exprimir essa experiência, a análise de Wittgenstein é essencialmente concebida para tratar das exteriorizações desta segunda classe, e é para estas, pois, que é proposta a tese da eliminabilidade da expressão do autoconhecimento. 
Para compreender a natureza puramente expressiva das exteriorizações, convém recordar os resultados da sinopse da Teoria do Sentido, e recordar que o sentido de um termo como «dor» é compreendido quando se compreendem as circunstâncias e o contexto com que a introdução do termo em $L$ está associada. A ideia de Wittgenstein é que a introdução do termo «dor» traz como consequência a introdução de uma nova forma de comportamento a ser observável durante a experiência de dor, em particular, o termo «dor» é introduzido de facto como uma substituição das expressões orgânicas e inarticuladas de dor, como gritar ou chorar. Assim, segundo o parágrafo 224 de Philosophische Untersuchungen o termo da linguagem $L$ não é uma descrição do comportamento ou da experiência de dor, mas é antes para ser considerado como tendo a natureza lógica de um grito, que o termo de resto é suposto substituir e, portanto não pode ser interpretado como uma asserção à qual um valor de verdade será atribuído. Assim, à luz da nossa premissa, não faz sentido duvidar se Job está ou não enganado quando diz que está em dor ou, o que seria o mesmo, não faz sentido perguntar se Job não se terá enganado ao chorar a sua dor ${ }^{19}$.

Presumida a existência de um comportamento associado com a experiência de dor, em si próprio orgânico, seria de concluir a impossibilidade de ensinar ou introduzir em $L$ um termo como «dor», cujo sentido é essencialmente determinado pelo facto de podermos associar o termo com as diferentes manifestações orgânicas de dor, e em relação às quais justificamos a introdução e a explicação do sentido do termo. Como é tornado óbvio no parágrafo 288 de Philosophische Untersuchungen, a explicação do sentido do termo não é por si suficiente para garantir a assimilação correcta do termo, uma vez que qualquer explicação pode ser correcta ou incorrectamente assimilada. Só o comportamento subsequente da pessoa a quem damos esta explicação do sentido do termo «dor» pode levar a decidir se a sua assimilação foi correcta ou incorrectamente realizada. Finalmente recordamos que não podemos regressar à concepção já rejeitada de que a compreensão do sentido deste termo é explicável por referência ao acto de visualização que ocorre na minha consciência quando eu emprego o termo, uma vez que, como sabemos, nem a experiência

${ }^{19}$ A relação entre o conhecimento de si próprio e o emprego do conceito de critério entendido como o par $\left\langle K_{i}, P\right\rangle$ é elegantemente exposto por Shoemaker, Sydney, «Self-Reference and Self-Awareness» in The Journal of Philosophy, volume LXV, n. ${ }^{\circ} 19,1968$. 
privada de dor nem a imagem mental privada são essenciais na elucidação do sentido do termo. No parágrafo 271 de Philosophische Untersuchungen refere-se Wittgenstein, num exemplo, a uma pessoa que não conseguisse conservar na sua memória o sentido do termo «dor», que utilizasse o termo «dor» a propósito dos objectos mais variados, mas que no entanto também o empregasse em conformidade com o seu uso e as pressuposições correntes ${ }^{20}$. No exemplo, o sentido que a pessoa não consegue conservar na memória não é pois o sentido do termo como o delineamos no nosso primeiro capítulo, mas o sentido tal como é incorporado numa imagem mental privada que a pessoa tem que recordar para poder aplicar o termo. Mas uma vez que a utilização do sentido do termo em situações reais pode, ex hypothesi, variar de objecto para objecto sem que no entanto a pessoa deixe de observar o seu emprego correcto, deixa de ser necessário pressupor a hipótese redundante de que o sentido do termo não é conservado na memória e, assim, a sua compreensão não pode também depender desta circunstância.

Wittgenstein considera um outro aspecto da análise de declarações da forma geral «X tem dores», nomeadamente o estatuto lógico do sujeito da função proposicional « $X$ tem dores». Considerando que $X$ toma valores num domínio de seres humanos, Wittgenstein procura determinar as consequências que se seguem quando $X$ é substituído por «eu» ou por «Job» ${ }^{21}$. Em particular quando $X$ é substituído por «eu» e eu afirmo, «eu tenho dores» não é necessariamente o caso que eu saiba quem tem as dores que eu digo ter. Em conformidade com o nosso postulado de que aquilo de que não posso ter dúvidas também não posso ter a certeza e aquilo de que não posso ter a certeza também não posso conhecer, segue-se que na expressão «eu tenho dores» o termo «eu» não designa uma pessoa, uma vez que não existe um critério que identifique a pessoa de que eu afirmo ser o sujeito da experiência das dores, visto que, de mim próprio, não posso duvidar se estou ou não a ter as dores que digo que tenho.

${ }^{20}$ Uma variante do problema da inversão do espectro, em que se supõe que o sentido privado das palavras que têm como referência as cores do espectro difere de pessoa para pessoa, embora se consiga alcançar acordo quanto ao uso intersubjectivo das palavras em questão. Logo, o uso corrente é conservado mas as imagens mentais privadas diferem uniformemente.

${ }^{21}$ A discussão mais completa do tema na literatura presente é Shoemaker, Sydney, Self-Knowledge and Self-Identity, Cornell University Press, Ithaca, Nova Iorque, 1963. 
Em contraste com as exteriorizações, as declarações expressas na terceira pessoa do singular são autenticamente descritivas e não apenas expressivas, e por isso tem sempre sentido perguntar-se de quem é que se fala quando se diz que Job tem dores e o que é que se lhe atribui ao dizer-se que Job tem dores. Assim a proposição «Job tem dores» não pode pois ser considerada como uma reformulação da expressão espontânea e orgânica de dor de Job e por isso tem que se determinar a referência da palavra «dor» neste contexto. Excluída a possibilidade de explicar a referência da palavra «dor» apelando para a experiência interior de Job, à qual só ele pode ter acesso, não resta senão tentar pô-la em conexão com o comportamento de dor que Job ostensivamente mostra. No entanto, este comportamento, como já tivemos ocasião de fazer notar, não é para ser interpretado à luz da doutrina behaviorista, mas antes como sendo a união do comportamento observável e do uso de um critério expresso na linguagem $L$ que permite, por um lado, a identificação do sujeito da experiência de dor como sendo Job e, por outro lado, permite a identificação de «dor» como sendo o conteúdo da experiência de que Job é sujeito. Nestas circunstâncias, pois, a declaração feita com o emprego da terceira pessoa do singular é para ser considerada como uma proposição genuína e portanto susceptível de ser portadora de um valor de verdade. Neste caso também o nosso postulado conduz a uma decisão acerca da questão de determinar o sentido do meu conhecimento da dor de Job, uma vez que, acerca de Job, já faz sentido eu duvidar quem é o sujeito da experiência e/ou de que experiência se trata. Esta dúvida uma vez eliminada conduz à declaração verificavelmente verdadeira de que Job tem a experiência de dor.

Concluímos este parágrafo pela alusão ao problema da ordem entre o argumento contra a existência da linguagem $L_{p}$, e a doutrina da eliminabilidade da expressão de autoconhecimento. O problema em si consiste em saber se as proposições em questão são deduzíveis uma da outra e, em caso afirmativo, qual é a proposição que se utiliza como premissa. Este problema não seria sequer posto se, como facto da experiência, as proposições que exprimem uma pretensão de se ter alcançado autoconhecimento tivessem um único emprego, nomeadamente, o de funcionarem como uma expressão de dor. Ao contrário, é um facto da experiência linguística que eu posso usar uma dessas proposições, como «eu sei que tenho uma dor de cabeça» num contexto em que se torna óbvio que não estou a ter a pretensão de ter alcançado conhecimento acerca de mim próprio. A proposição pode 
ser apenas usada, por exemplo, para exprimir um motivo ou um fundamento justificativo da minha actuação, como quando digo «eu sei que tenho uma dor de cabeça» para justificar o motivo pelo qual não devo aceitar a proposta de ir sair.

Tem-se igualmente como um facto da experiência linguística que o emprego deste género de proposições poder ter um fim genuinamente descritivo, como é o caso quando eu tenho que relatar ao meu médico a configuração precisa da minha dor de cabeça a fim de poder vir a receber um tratamento adequado. Para estas proposições temos como um resultado geral que a doutrina da eliminabilidade da expressão do autoconhecimento é falsa, uma vez que para estes casos temos que considerar as proposições como sujeitas ao princípio do terceiro excluído. Mas do facto de a doutrina ser falsa para estas proposições não se infere que o argumento contra a existência de $L_{p}$ seja falso, uma vez que o que se está a garantir a estas proposições é a representabilidade em $L$. Ao aceitarmos a representabilidade destas proposições em $L$ não estamos, de modo algum, a afirmar a existência possível de $L_{p}$ dado que é possível, à maneira de Kant, manter que uma condição de possibilidade da minha experiência é o reconhecimento da minha possibilidade de imputar experiências a outrem. Deste modo posso definir um contraste radical entre o uso de $L$ e o uso de $L_{p}$, uma vez que, relativamente a $L$, eu sei que tenho determinada experiência e que Job tem uma determinada experiência, e o meu saber acerca de mim é o mesmo que o meu saber acerca de Job. Por contraste, em $L$, só posso saber acerca de mim que tenho uma determinada experiência e tenho que ser céptico relativamente à minha possibilidade de o saber acerca de Job. Logo só posso negar a possibilidade de conhecimento acerca de Job se nego a possibilidade de conhecimento acerca de mim próprio. Assim para determinar o que se passa na consciência de Job, usando uma inferência tradicional per analogiam só me é possível quando eu estou em condições de determinar o que se passa na minha própria consciência. Mas evidentemente se me é possível saber o que se passa na minha própria consciência não preciso da inferência per analogiam para estabelecer o que se passa na consciência de Job.

Finalmente para aquelas proposições que exprimem uma pretensão actual de autoconhecimento, a validade do argumento contra a existência de $L_{p}$ implica a verdade da doutrina da eliminabilidade da expressão de autoconhecimento. Com efeito, como vimos durante a exposição do argumento contra a existência de $L_{p}$, este argumento depende da rejeição da pretensão da privacidade epistemológica. Se a 
doutrina acerca da eliminabilidade da expressão de autoconhecimento fosse falsa, então seria possível interpretar estas proposições como sendo expressões de conhecimento a que só o sujeito poderia em princípio ter acesso. Estas proposições seriam então inevitavelmente apenas representáveis em $L_{p}$. Mas em $L_{p}$, ex hypothesi, não tem existência possível. Logo se não pode haver uma linguagem como $L_{p}$ também não pode haver privacidade epistemológica, e não havendo esta também não me é dado saber se tenho ou não a experiência que digo estar a ter. Portanto a doutrina da eliminabilidade da expressão de autoconhecimento é verdadeira para as proposições que exprimem uma pretensão actual de autoconhecimento se o argumento contra a existência de $L_{p}$, for verdadeiro.

Em relação à primeira classe de proposições, i.e., aquelas em que se pode inferir do contexto que o princípio do terceiro excluído se lhes aplica, a doutrina da eliminabilidade da expressão do autoconhecimento não é aplicável e o problema de sua derivação a partir do argumento contra a existência de $L_{p}$ não se coloca.

\section{A relação de critério $<K_{i}, p>$ e o princípio $D_{i}(S) \leftrightarrows$ $D_{t} \cup_{k}(S)$}

Concluímos com uma referência ao emprego do termo «critério» feito por Wittgenstein ao longo do argumento contra a existência da linguagem $L_{p}$ e da sua doutrina acerca da eliminabilidade da expressão de autoconhecimento.

O aspecto mais imediatamente óbvio em relação ao emprego do termo «critério» por Wittgenstein é a introdução do contraste entre um critério e um sintoma. Num exemplo conhecido, a baixa de pressão num barómetro pode ser usada como um sintoma de chuva; analogamente, as transformações eléctricas e químicas das células do meu cérebro podem ser usadas como um sintoma de que estou a ver um cravo. A baixa pressão do barómetro e as transformações eléctricas e químicas do meu cérebro não são, no entanto, critérios que permitem determinar se chove ou se estou a ver um cravo. A chuva torna-se manifesta para mim através das minhas diversas impressões e adaptações que me são forçadas pelas circunstâncias; analogamente, apercebo-me de que tenho diante de mim um cravo sem necessariamente ter que ter uma ideia da configuração eléctrica e química do meu cérebro neste momento. Assim um critério é uma norma de 
procedimento, incluindo o uso da linguagem, por meio da qual se torna possível determinar com decisiva evidência se estou ou não em condições de poder afirmar uma proposição dada $P^{22}$. A relação entre a proposição $P$ e um critério $C_{i}$ para $P$ não é unívoca uma vez que, à luz do parágrafo 164 de Philosophische Untersuchungen, os critérios dependem das circunstâncias e em condições diferentes definem-se critérios diferentes.

Como já tivemos a ocasião de ver, um critério para identificar uma sensação é uma norma de procedimento que nos leva a poder dizer de que sensação se trata; ou, num outro exemplo, um critério para declarar duas funções como idênticas é uma norma de procedimento que nos leva a poder dizer que as duas funções são as mesmas; um critério para decidir da correcção de uma memória é uma norma de procedimento que nos leva a poder dizer se a memória é ou não a memória correcta.

Um critério difere de um sintoma pelo facto de ser uma norma decisiva de evidência. Num exemplo conhecido de Wittgenstein em Philosophische Bemerkungen, um critério para se poder determinar se eu sofro ou não de angina é a descoberta do bacilo no meu sangue, de tal modo que dizer «eu tenho angina se tiver bacilo» é uma tautologia; assim, ao encontrar-se o bacilo encontrou-se a evidência decisiva para se poder justificar a minha afirmação «tenho uma angina». Mas a noção de critério como evidência decisiva tem que ser reconciliada com a noção anteriormente mencionada de que a relação criterial não possui a propriedade de univocidade; assim, se um critério é evidência decisiva para poder afirmar uma dada proposição $P$, parece seguir-se que não pode haver mais do que um critério. A demonstração desta aparente impossibilidade é fácil conduzir; basta apelar nomeadamente para o facto de que a existência de, digamos, dois critérios, sugere imediatamente a questão de saber se são ou não entre si inconsistentes, uma hipótese para qual não parece haver uma razão para ser rejeitada in limine. Se os critérios estão em conflito então um pelo menos não pode ser considerado como proporcionando evidência decisiva, o que demonstra a nossa proposição. Vale a pena reparar que o mesmo argumento obtém quando se substitui a expressão «evidência decisiva» por a «melhor evidência possível».

\footnotetext{
${ }^{22}$ Acerca do uso da relação de critério na refutação da existência da linguagem $L_{p}$ ver Kenny, Anthony, «Criterion» in Encyclopaedia of Philosophy, org. Paul Edwards, Nova Iorque, pp. 258 e segs.
} 
O processo que é de presumir que Wittgenstein tem em mente é o de conceber a relação criterial, i.e., a relação entre os dois critérios putativos $K_{1}$ e $K_{2}$ e uma proposição $P$ que eu me considero à sua luz justificado em afirmar, como sendo a relação que se obtém quando de $K_{1}$ ou $K_{2}$ se pode afirmar $P$ e de não- $K_{1}$ e não- $K_{2}$ não se segue que eu afirme não- $P$; logo, é uma relação segundo a qual $K_{1}$ e $K_{2}$ não estabelece necessariamente $P$ e, por sua vez, não- $K_{1}$ e não- $K_{2}$ não estabelece necessariamente não- $P^{23}$. Por outro lado, através de exemplos dados por Wittgenstein em Philosophische Untersuchungen, chega-se à noção de que aquilo que eu digo é efectivamente um critério para determinar as imagens mentais que eu tenho neste momento na minha consciência; mas o facto de eu dizer que neste momento tenho uma imagem mental do Sol na minha consciência não estabelece decisivamente que eu tenho uma imagem mental do Sol neste momento na minha consciência, uma vez que eu posso estar enganado ou a mentir deliberadamente. Como vimos durante o argumento contra a existência de $L_{p}$, uma memória não pode ser um critério para a identificação de uma sensação visto que uma memória não é evidência decisiva para estabelecer a existência da sensação, uma vez que cada memória requer por sua vez um critério para estabelecer sua correcção. Assim concluímos que a relação criterial não é a relação de implicação.

A expressão «norma de procedimento» pode agora ser considerada com mais pormenor. Com ela temos em mente a ideia de que um critério é para ser agora concebido como um critério definidor e este por sua vez consiste num método de determinação do fenómeno que fornece a evidência decisiva que procuramos. No parágrafo 354 de Philosophische Untersuchungen Wittgenstein afirma que a existência simultânea de critérios e de sintomas arrasta consigo a consequência indesejável de obliterar o conceito de critério, criando a impressão falsa de que só há sintomas. Num exemplo já mencionado, a experiência mostra que quando a pressão baixa há chuva, mas também mostra que há chuva quando eu me sinto molhado. Normalmente rejeita-se a minha impressão de que estar molhado é um critério de ter chovido pelo facto de os dados dos sentidos poderem ser uma fonte de erro. Mas como é que eu me posso dar a ilusão de que chove senão pelo uso do critério definidor? E óbvio que os dados imediatos

\footnotetext{
${ }^{23}$ Nestes termos a relação de critério poderia ser representada pela conjunção $\left(\left(K_{1} \vee K_{2}\right) \rightarrow P\right) \wedge \sim\left(\left(\sim K_{1} \wedge \sim K_{2}\right) \rightarrow \sim P\right)$.
} 
dos sentidos não são evidência decisiva de chuva. Mas a diferença entre critérios e sintomas consiste em que o valor evidencial dos sintomas é apreendido na experiência enquanto o valor da relação criterial enquanto evidência decisiva depende de uma definição. Se $K_{i}$ é um critério para $P$ então é necessário que $K_{i}$ é evidência para $P$. Como a notação implica, pode haver mais do que um critério para $P$. Logo $K_{i}$ é um critério para $P$ se e somente $K_{i}$ constitui evidência imediata e não indutiva da verdade de $P$.

Resta observar finalmente, para caracterizar o uso do termo, que ao falar-se de critério se tem em mente não só o fenómeno ou fenómenos que são para ser considerados como proporcionando a evidência decisiva que procuramos, mas também a representação verbal do critério definidor, o que implica um uso do termo que é idêntico ao uso do termo «critério» em matemática. Assim a proposição necessariamente verdadeira que representa a relação de evidência entre $K_{i}$ e $P$ é também para ser considerada como sendo um critério para $P$. A natureza da relação que Wittgenstein supõe existir entre $K_{i}$ e $P$ é puramente convencional. $K_{i}$ é estabelecido por mim num acto livre de escolha e pode ser ab-rogado por mim quando eu quiser. Mas $K_{i}$ não é um critério para $P$ se eu conseguir chegar a compreender o sentido de $P$ sem ter compreendido previamente a relação que existe entre $K_{i}$ e $P$.

O conceito de critério, na filosofia da consciência de Philosophische Untersuchungen, é normalmente identificado com um fenómeno observável, o que necessariamente é evidência da existência de um estado de consciência, ou de um processo de consciência em si próprio inobservável. Deste modo, o critério para determinar a cor da imagem que Job tem em mente neste momento é o que eu oiço e vejo Job fazer, uma vez que não posso observar directamente a cor da imagem que Job diz ter. Em geral, segundo o parágrafo 269 de Philosophische Untersuchungen, temos ao nosso dispor critérios que permitem deduzir, do comportamento de Job, o facto de ele pensar que compreende o sentido da expressão que eu uso, o facto de ele atribuir à minha expressão um sentido que não é o sentido correcto e finalmente o facto de compreender correctamente o sentido da expressão que eu uso. A ideia geral é que a determinação da existência de um processo da consciência só pode ser feita recorrendo a um critério no sentido do parágrafo 269 de Philosophische Untersuchungen. Vale a pena reparar que embora os critérios para a aplicação de um termo sejam formulados em termos de comportamento, não se segue necessariamente que o termo assim introduzido seja ele próprio uma descrição 
de comportamento. Como já tivemos a ocasião de expor, o facto de $K_{i}$ ser um critério para $P$ não é para ser identificado como sendo $K_{i} \mathrm{o}$ sentido de $P$. O comportamento de dor de Job é um critério para determinar a existência da experiência de dor de Job, mas o termo «dor» não tem como sendo o seu sentido o comportamento de dor de Job. Segundo Wittgenstein é necessariamente verdadeiro que o comportamento de Job é evidência da sua experiência, mas evidentemente isto não é o mesmo que dizer que o termo «dor» significa o choro de Job. Pelo contrário, como vimos durante a exposição da doutrina da eliminabilidade da expressão de autoconhecimento, a expressão verbal substitui o choro, não é a sua descrição.

Foi já proposta a ideia de que, na filosofia da consciência, um critério não tem que ser necessariamente ele próprio observável. Assim propõe-se que um critério para determinar se eu compreendo a regra de Modus Ponens consiste no facto de se estar em condições de determinar se eu domino a regra. Mas dominar uma regra é possuir uma faculdade a qual ela própria não pode ser observada mas apenas inferida. O erro aqui consiste em tentar determinar o critério como sendo a faculdade. Como já foi dito, um processo interior não é um critério; ao contrário é para se estabelecer a sua existência que se tem que introduzir critérios. Assim, se a existência da faculdade se infere do seu exercício, é o seu exercício que tem que ser considerado como critério e portanto é observável.

Igualmente proeminente é o uso da relação de critério entre a fórmula $K_{i}$ e uma proposição $P$ durante a demonstração do argumento contra a existência da linguagem $L_{p}$. Como vimos, Wittgenstein argumenta que é impossível proporcionar uma definição ostensiva privada de uma sensação $S$, porque uma definição $D_{t}(S)$, i.e., a definição da sensação $S$ no momento $t$, para ser adequada tem que satisfazer a condição $D_{t}(S)$ ser equivalente a, para qualquer $k, D_{t} \cup_{k}(S)$. Mas é evidentemente que se $S$ é um acontecimento privado e incomunicável, não existe um critério $K_{i}$ que garantira a associação de « $S$ » com a sensação original. A memória do sujeito não pode funcionar como sendo $K_{i}$ uma vez que cada recordação necessita por sua vez de um critério para a legitimar como correcta e cairíamos assim num regressus ad infinitum. Por outro lado, quando o que há a recordar é um objecto privado, não há possibilidade de distinguir uma memória exacta de uma memória ilusória. Logo, a definição privada ostensiva $D_{t}(S)$ não pode ser efectuada. 
Assim parece ser possível deduzir do argumento contra a existência de $L_{p}$ que um conceito $C$ é vazio se não existe um critério $K_{i}$ tal que $\left(K_{i}, C\right) . K_{i}$ tem que ser concebido pois como evidência não indutiva para a legítima aplicação de $C$. No Capítulo 3 de Espontaneidade da Razão discutiremos alguns dos aspectos do uso desta ideia em Lógica.

Wittgenstein não pretende afirmar que um conceito $C$ que tem um critério $K_{i}$ é sempre empregue com base em $K_{i}$. Pelo contrário, os conceitos de dor, de imagem mental, por exemplo, têm critérios que no entanto não são empregues por mim quando falo acerca de minhas dores e das imagens mentais que tenho neste momento na minha consciência. Uma observação, feita na terceira pessoa do indicativo, difere de uma asserção feita na primeira pessoa do indicativo acerca de uma impressão sensorial, pelo facto de aquela poder ser feita sem o recurso a qualquer inferência; difere ainda da asserção feita na primeira pessoa por só poder ser legitimada pelo recuso à evidência e, assim, a um dado $K_{i}$. E claro que $K_{i}$ pode ser ele próprio uma impressão sensorial caso em que o sujeito não o pode reconhecer através de, digamos, $K_{i}$. No entanto os conceitos usados para falar acerca de $K_{i}$, $\mathrm{K}_{j}$, etc., têm que ser eles próprios legitimados por novos critérios.

Parece ser seguro representar a posição de Wittgenstein como sendo a de que, supondo assegurada a igualdade entre critério e evidência conclusiva, uma modificação num critério $K_{i}$ para um conceito $C$ implica uma modificação no sentido de $C$. Um processo para determinar se $K_{i}$ é um critério para uma proposição $P$ consiste em ver se é possível descobrir empiricamente que $K_{i}$ não é evidência a favor de $P$. Assim não é possível separar $K_{i}$ de $C$ sem alterar o sentido de $C$. Ao contrário, como já foi dito, uma vez que $K_{i}$ não é o único critério para $C$, tem-se que é concebível juntar a $K_{i}$ critérios $K_{j}, K_{l}, \ldots$, etc., para $C$ sem alterar o sentido de $C$.

M. S. Lourenço Universidade de Lisboa 